\title{
'Don't judge by outer appearance': Food promotion to children through food packages in the Sri Lankan market
}

\author{
Manori Gamage $e^{1}$
}

Sri Lanka Journal of Child Health, 2021; 50(1): 49-55
DOI: http://dx.doi.org/10.4038/sljch.v50i1.9402

(Key words: child food, marketing strategies, Sri Lankan market, WHO- NPM)

\section{Introduction}

Childhood obesity is a major public health problem throughout the world ${ }^{1}$. One major factor contributing to this problem is marketing strategies used to promote unhealthy food among children ${ }^{2}$. Food marketing has been shown to have a major influence on children's awareness on food and food choices, and a wide variety of food brands and food items are marketed using child focused marketing strategies $^{2,3}$. Some studies have already shown that most of these food items targeting children are unhealthy, and contain high levels of fat, sugar and salt ${ }^{2,4}$. Television was the commonest medium used to market child targeted food and beverages for decades $^{2,4}$. However, current trend is moving towards other channels like internet, child magazines and onsite promotions at supermarkets and shopping malls ${ }^{4,5}$. Marketing research has shown that companies tend to invest more funds on supermarket promotions than all other modes, because it has been shown that the influence is more when any item is promoted at the time of purchase $^{6,7}$. The best methods to advertise or promote child targeted food items at the time of purchase are attractive packages, attractive "health" claim or attractive promotional item attached to the specific product ${ }^{6,8,9}$.

Out of the above child targeted marketing strategies, product package plays a major role ${ }^{6,8,9}$. It significantly influences the act of purchasing, as $85 \%$ of the super market buying is made on impulse at the time of purchase ${ }^{10}$. Out of all consumers, children could be influenced by product packages very effectively ${ }^{11}$. It is found that the budget allocated for child-oriented food packing is on the rising trend, while expenditure on traditional advertising media is on the declining trend ${ }^{3,11}$. Some of the marketing strategies used on packaging targeting children are: famous cartoon characters, promotional items attached to the product, games or puzzles on the package and promotional codes which allow them to purchase or win one of their favourite items like video games or movie tickets ${ }^{1,6-9}$. It has been shown that cartoon characters have a strong influence on recognition of brands. In addition to the above, most of the child 
targeted food packages influence parental purchasing decisions through different claims mentioned on them ${ }^{1,12,13}$. Some of these are found to be only promotional claims and do not highlight the true quality of the food which is being promoted $^{13,14}$. Some popular health claims mentioned on the food packages are: "provides daily vitamin / calcium requirement", "rich in fibre", "no artificial flavours / colours / preservatives". This technique has been shown to induce a cognitive bias and create a positive impression of the specific food. This is known as "health halo effect"15.

It has been shown that these child targeted marketing of unhealthy, energy dense, food that are high in salt and sugar need to be regulated closely ${ }^{16}$. Several countries have already introduced policies to regulate child targeted food advertising ${ }^{17,18}$. In addition, various nutrient profile models (NPMs) are proposed to assess the true quality of food which target children ${ }^{18,19}$. According to these models, food items are assessed to see the suitability of their nutritional composition to children. One well-recognized NPM used by many countries is the one proposed by the World Health Organization (WHO) ${ }^{20,21}$. In addition, different countries have adopted their own NPMs to regulate food marketing targeted for children $^{22}$. The NPM system suggested by WHO for South East Asian region indicates the permitting criteria needed for a food item to be suitable for marketing to children ${ }^{23}$. It mainly analyses total fat, total sugar, added sugars, saturated fat, sodium, and energy per $100 \mathrm{~g}$ of the product, and has provided different threshold values for different food groups. However, when compared to other NPMs, our regional one is incomplete, and has several gray areas with a lot of loopholes which food advertisers can easily exploit.

To apply or implement regulatory action on childhood food marketing strategies according to any NPM, it is mandatory to identify the different methods manufacturers use to promote food items and what their true nutritional value is. Unfortunately, there are hardly any data available in the local literature regarding the above, so this was conducted as a preliminary study to identify the child focused marketing strategies used by food packaging and health claims in the Sri Lankan market. As a secondary measure, we tried to analyse their suitability for marketing according to the WHO NPM suggested for our region.

\section{Objectives}

To identify the child focused marketing strategies used by food packaging and health claims in the Sri Lankan market and to analyse their suitability for marketing according to the WHO NPM suggested for our region.

\section{Method}

A cross sectional survey of packaging analysis and content analysis marked on the package of food products especially marketed for children was performed at four leading supermarket chains operated in Sri Lanka.

\section{Selection of food items}

Main super store of each supermarket chain was selected. Each of the food aisles was assessed and food items were selected according to the following criteria which were adapted from previous similar studies conducted on child targeted food items ${ }^{16}$.

1. Food items with packaging containing cartoons, puzzles, games, toys, collecting items like cards or vouchers, water bottles, stationary items etc. which attract children to the particular food item.

2. Food items promoted for children with claims as "healthy "or "good for children."

3. Food items commonly consumed by children such as cereals, yoghurts, ready to eat meals like instant noodles and precooked meat products and other dairy products if they do not belong to above two categories.

Following food items were excluded

1. Food items used for children less than 12 months as they are already regulated

2. Food items like cakes, biscuits, chips, soft drinks, confectionary items like chocolates and toffees which are already considered as 'unhealthy'

3. Fresh fruits and vegetables

One food item was recorded once, and when the same product had different sizes, only one size was selected. Products of the same brand with same nutritional value with different flavours were recorded only once

Data collection: Following data were collected from the selected food items:

a. Nutritional information per $100 \mathrm{~g}$ according to the packaging.

b. All sides of the packing were analysed for promotional or marketing strategies like cartoons, games and puzzles, attached promotional items.

c. All claims or phrases related to health, nutrition and content.

Ethical issues: Ethical clearance was obtained from the Ethics Review Committee of the Faculty of Medical Sciences, University of Sri Jayawardenepura (No. ERC/FMS/USJ/44/19) on 30.08.2019. 


\section{Results}

In four leading super market chains operated in Sri Lanka, 75 products were identified, which were within our inclusion criteria. There were 27 breakfast cereal products, 24 milk and milk based products and 24 ready to eat category food items (Table 1). Each product was analysed with regard to the child attracting marketing strategies and health claims on their packaging which could influence children or parental purchasing decision.

Table 1: Number of products targeted at children under different categories

\begin{tabular}{|l|c|}
\hline \multicolumn{1}{|c|}{ Food category } & $\begin{array}{c}\text { Products } \\
\text { n (\%) }\end{array}$ \\
\hline Breakfast cereals & $27(36)$ \\
\hline Milk and milk based food & $24(32)$ \\
\hline Ready to eat & $24(32)$ \\
\hline Total & $75(100)$ \\
\hline
\end{tabular}

The commonest mode used to attract children in all product categories was the attractive package with cartoon characters. Out of 75 products 41 (54.7\%) had used this strategy and some of these characters were further promoted as heroes. Attaching gift items and promotional codes on the package was the next common child targeted marketing strategy found in the Sri Lankan market. Most of the products had paid special attention to different types of claims on the packages, which were more powerful in influencing parental purchasing decisions. On the 75 products analysed, there were 103 claims.

\section{Breakfast cereals}

Out of breakfast cereals, 74\% (20/27) had used cartoons on their package to attract children and some of these characters were further promoted on television advertisements as heroes with super power. During the period we conducted our survey, there were no promotional items attached to any of the breakfast cereals available in the super markets. In one super store, a limited number of packages of one brand was promoted with the theme "buy one get one free". Two of the breakfast cereal brands had pieces of a jigsaw puzzle printed on their packages. These could be completed by cutting them out of the package and when completed, showed a very healthy and active character who eats the particular cereal inside the package (Table 2).

Table 2: Methods of package promotion for children

\begin{tabular}{|l|c|c|c|}
\hline Features in the packaging to attract children & $\begin{array}{c}\text { Breakfast cereals } \\
(\mathbf{n = 2 7})\end{array}$ & $\begin{array}{c}\text { Milk/milk based } \\
\text { food (n= 24) }\end{array}$ & $\begin{array}{c}\text { Ready to eat } \\
(\mathbf{n = 2 4 )}\end{array}$ \\
\hline Cartoons on package & 20 & 08 & 13 \\
\hline Games on package & 02 & - & none \\
\hline Puzzles on package & 03 & - & None \\
\hline Gifts attached & - & 03 & 01 \\
\hline Gift /vouchers attached & - & 02 & None \\
\hline Collectable items given with the package & - & 03 & None \\
\hline Stationary items given with the product & - & 01 & 02 \\
\hline
\end{tabular}

In 27 products analysed, there were 36 nutritional or content claims. Out of the nutritional promotional claims $37 \%(n=10 / 27)$ have claimed that their product is rich in micronutrients and the commonest micronutrient they tried to promote was iron and in some it was highlighted with large bold letters as "iron shakthi“". The other health claims which were promoted are as shown in Table 3.

When breakfast cereals were assessed according to the WHO NPM for the Asian region, 3 products had total fat content above the recommended value $(>12 \mathrm{~g} / 100 \mathrm{~g})$ while 20 products out of 27 had sugar content above the permitted range $(>9 \mathrm{~g} / 100 \mathrm{~g})$. Although energy content is an important aspect of a product marketed for children in our regional NPM document, energy content for breakfast cereals was not specified and was not restricted ${ }^{23}$.

\section{Milk and milk based food items}

There were 24 dairy related food items. They were flavoured and unflavoured milk packets, cheese, yoghurts, butter and other bread spreads. Out of them only $1 / 3^{\text {rd }}$ had used cartoon characters to promote the packages. Three of these products had used other promotional items attached to the packages and these were further promoted by providing different colour or design items attached to the same product and used the promotional claim "collect all 4 colours or 4 designs " by persuading children to buy more from the same brand (Table 2).

Milk and milk based products had mainly used health claims to influence parents. Of them $41.6 \%$ $(n=10)$ promoted their brand claiming it contains micronutrients (vitamins/minerals) needed for children to grow healthy and 8 brands promoted them claiming their product had power to boost immunity. Some brands claimed that they provide probiotics to protect the gut of the child. As most of 
the parents were aware that high sugar content has adverse outcomes, a few products $(2 / 24)$ had claimed that their product did not have added sugar.

We identified that most of the milk and milk based drinks in our study sample had sugar content above
$6 \mathrm{~g} / 100 \mathrm{~g}$, which is the generally accepted sugar content for food marketed for children ${ }^{23}$. When grouped together mean sugar content was $13.8 \mathrm{~g} / 100 \mathrm{~g}$ and this is more than double the accepted amount.

Table 3: Different types of claims used to promote food items to children

\begin{tabular}{|l|c|c|c|}
\hline Type of claims & Milk \& milk related & Breakfast cereal & Ready to eat meals \\
\hline Healthy/nutritional & & & - \\
\hline References to healthfulness & $3 / 24$ & - & - \\
\hline Reference to immunity & $5 / 24$ & $6 / 27$ & $4 / 24$ \\
\hline Added vitamins/minerals (micronutrient) & $10 / 24$ & $10 / 27$ & - \\
\hline Reference to neurodevelopment & $8 / 24$ & $4 / 27$ & - \\
\hline Contain probiotics & $5 / 24$ & - & - \\
\hline Ingredient claims & & $5 / 27$ & - \\
\hline More fibre & - & & $8 / 24$ \\
\hline No added sugar & $2 / 24$ & - & $8 / 24$ \\
\hline No preservatives & $4 / 24$ & - & \\
\hline No artificial colours or flavours & $4 / 24$ & $5 / 27$ & \\
\hline Low fat /cholesterol free & & $4 / 27$ & \\
\hline $\begin{array}{l}\text { Other } \\
\text { a. Made with real grain }\end{array}$ & $2 / 27$ & \\
b. Made with real fruit puree & & & $2 / 24$ \\
c. Pure Sri Lankan product & & & \\
\hline
\end{tabular}

\section{Ready to eat food products}

Among 24 products, there were different kinds of instant noodles, pre-cooked meat products and frozen food items with minimal preparation. Out of them, half of the products had packages with pictures, which attract children (Table 2). The next common marketing strategy used was printing different claims on the package. Some of those claims were related to the non-nutritional content of the product and some of them claimed: "no preservatives, no artificial flavours or no artificial colours". Out of 24 products identified in this group, only 4 had claimed on the micronutrient content of their product. During analysis of ready to eat food quality according to the WHO NPM for the region, total fat, sugar, and sodium content were within the accepted values.

\section{Discussion}

In the Sri Lankan market, the number one method $(74 \%)$ used to promote breakfast cereal was cartoon characters. This trend was seen in other published studies, where the percentage varied between 81-96\%, while Garcia AL et al has shown that this is $100 \%$ in the UK market ${ }^{1,16,17,20}$. Out of 27 products, all were promoted by either nutritional or content claims. Out of them, the most used claim was presence of micronutrients $(37 \%)$. In a study done in UK, micronutrient promotion was detected in $64.4 \%{ }^{18}$ of breakfast cereals while a study in Uruguay has detected this on $46-54 \%$ of products ${ }^{1}$.
When milk and milk based products were considered, commonest marketing strategy used was nutritional claims which were mainly targeted to parents. Out of 24 products $41.6 \%(n=10)$ had nutrient claims on their packages. One study from Uruguay showed similar results with $46 \%$ using nutrient claims while a study in UK has shown a value double this with $86.7 \%$ promoted with nutrient claims ${ }^{1,16}$.

During analysis of ready to eat meals it was shown that just more than half of them (13/24) were promoted through child friendly packaging. In a UK based study it was shown that all products had child friendly designs like cartoons, while in a study conducted in Uruguay it was recorded as $75 \%{ }^{1,17}$. Food belonging to this group found in Sri Lankan market has mainly used content claims $(66.6 \%)$ to promote them more than the nutrient claims (17\%) (Table 3). Similar pattern was seen in a study done in Uruguay where it was shown that there were more content claims than nutrient claims in the ready to eat food group ${ }^{1}$. However, in a UK based study, $50.8 \%$ products had used nutrient claims while $31.1 \%$ had used content claims to promote their brands ${ }^{17}$.

Childhood obesity is a major challenge for the developing world due to high energy and sugar consumption ${ }^{1}$. Making matters more complicated, these energy dense food items were promoted for children with minimal regulations with above mentioned different marketing strategies. Although 
we have a WHO generated NPM for south-east Asia, a set of recommendations on the marketing of food and non-alcoholic beverages to children, to control or regulate food item promotion to children, it is incomplete as shown below ${ }^{23}$.

When assessing breakfast cereals, according to the WHO NPM for the Asian region, 3 products had total fat content above the recommended value $(>12 \mathrm{~g} / 100 \mathrm{~g})$ while 20 products out of 27 had sugar content above the permitted range $(>9 \mathrm{~g} / 100 \mathrm{~g})$. However, we noticed that these products were promoted openly without any restriction while NPM has a clause mentioned under each category as "marketing prohibited if thresholds exceed values per $100 \mathrm{~g}$ "24. With the background of childhood obesity it is important to publish a threshold value for energy content. However, in our regional NPM document, energy content for breakfast cereals was not specified and not restricted. This is only one factor we highlighted to demonstrate the incompleteness of our regional $\mathrm{NPM}^{23}$.

When analysed, the milk and milk based products, according to the WHO NPM, are grouped under milk and milk based drinks, curded dairy based food, cheese and analogues, fat and fat oils and fat emulsions (butter). Under none of the above mentioned groups, threshold values for sugar content and energy content were provided and only total fat content and the sodium content are used to monitor the suitability for marketing. Most of the milk and milk based drinks in our study sample had sugar content above $6 \mathrm{~g} / 100 \mathrm{~g}$, which is the generally accepted sugar content for food marketed for children ${ }^{24}$. The mean sugar content identified in this food group was $13.8 \mathrm{~g} / 100 \mathrm{~g}$ and this is more than double the accepted amount. Although these high sugar contents were mentioned on the packages, there were no restrictions to promote them since there is no organized regulatory body operating in Sri Lanka to scrutinize them. At one stage, the traffic light coding system was introduced to regulate the sugar content. However, during our assessment we noticed most of the milk based drinks which were high in sugar did not have any colour coding on them.

During analysis of ready to eat food quality according to the WHO NPM for the region, total fat, sugar, and sodium content were within the accepted values. The main concern which makes most of these food products unsuitable to promote among children is the high energy content. However, according to the WHO NPM, there was no threshold given for the energy content and hence there were no restrictions to promote them. This WHO NPM, which is the only one available for our region, has not addressed the health claims on food packages at all. In addition, there is no strategy to restrict attractive health claims on food packages, nor is there an operating regulatory body to measure the accuracy of such health claims. It is very important to regulate food promoting activities targeted on children. In addition, public should be empowered with appropriate awareness programmes regarding these regulatory criteria to make correct decisions and to report when it is breached.

\section{Conclusions}

The commonest mode used in the 4 supermarkets to attract children in all product categories was the attractive package with cartoon characters. Attaching gift items and promotional codes on the package was the next common child targeted marketing strategy

\section{Acknowledgements}

The author would like to thank Dr. Chadani Kodikara for support provided during data collection and the main four supermarkets for granting access to collect data needed for the study.

\section{References}

1. Gimenez A, Sladamando L, Curutchet MR, Ares G. Package design and nutritional profile of foods targeted at children in supermarkets in Montevideo, Uruguay. Cadernos de Saude Publica 2017; 33(5): e 00032116. https://doi.org/10.1590/0102311x0003211 6

2. Hastings G, Stead M, McDermott L, Forsyth A, MacKintosh AM, Rayner M, et al. Review of research on the effects of food promotion to children. Final Report. $22^{\text {nd }}$ September 2003. Available from: https://www.stir.ac.uk/media/stirling/servi ces/faculties/sport-and-health sciences/research/documents/FoodPromotion-to-Children-final_report_19_9.pdf

3. Institute of Medicine. 2006. Food Marketing to Children and Youth: Threat or Opportunity? Washington, DC: The National Academies Press.

4. Cairns G. Agnus K, Hastings G. The extent, nature and effects of food promotion to children. A review of the evidence to December 2008. Geneva: World Health Organization; 2009.

5. Harris JL, Pomeranze JL, Lobstein T, Brownell KD. A crisis in the marketplace: 
How food marketing contributes to childhood obesity and what can be done. Annual Review of Public Health 2008; 30: 211-25.

https://doi.org/10.1146/annurev.publhealth .031308 .100304

PMid: 18976142

6. Hawkes C. Food packaging: The medium is the message. Public Health Nutrition 2010; 13(2):297-9.

https://doi.org/10.1017/S13689800099931 68

PMid: 20082735

7. Moskowitz H, Reinr M, Lawlor JB, Deliza R. Packaging research in food product design and development. Hoboken: Wiley- Blackwell; 2009. https://doi.org/10.1002/9781444319330

8. Chacon V, Lenota P, Barnoya J. Child oriented marketing techniques in snack food packages in Guatemala. BMC Public Health 2013; 13:967-72.

https://doi.org/10.1186/1471-2458-13-967

PMid: 24139325 PMCid: PMC3853236

9. Hebden L, King L, Kelly B, Chapman K, Innes-Hughes C. A menagerie of promotional characters: promoting food to children through food packaging. Journal of Nutrition, Education and Behaviour 2011; 13:967-72.

https://doi.org/10.1016/j.jneb.2010.11.006 PMid: 21906547

10. Page R, Montgomery K, Ponder A et al. Targeting children in the cereal aisle: promotional techniques and content features on ready to eat cereal product packaging. American Journal of Health Education 2008; 39: 272-82.

https://doi.org/10.1080/19325037.2008.10 599050

11. Hawkes C. Sales promotions and food consumption. Nutrition Reviews 2009; 67: 333-48.

https://doi.org/10.1111/j.17534887.2009.0 0206.x

PMid: 19519674

12. Abrams KM, Evans C, Duff BRL. Ignorance is bliss. How parents of preschool children make sense of front of package visuals and claims on food. Appetite 2015; 87: 20-9. https://doi.org/10.1016/j.appet.2014.12.10

0

PMid: 25510529

13. Elliott C. Marketing fun foods: a profile and analysis of supermarket food messages targeted at children. Canadian Public Policy 2008; 34:259-73. https://doi.org/10.3138/cpp.34.2.259

14. Colby SE, Johnson L, Scheett A, Hovernson B. Nutritional marketing for food labels. Journal of Nutrition, Education and Behaviour 2010; 42:92-8. https://doi.org/10.1016/j.jneb.2008.11.002 PMid: 20096635

15. Whalen R, Harrold J, Child S, Halford J, Boyland E. The health halo trend in UK Television advertising viewed by children: The rise of implicit and explicit health messaging in the promotion of unhealthy foods. International Journal of Environmental Research and Public Health 2018; 15(3):560.

https://doi.org/10.3390/ijerph15030560

PMid: 29558457 PMCid: PMC5877105

16. Metha K, Phillips C, Ward P, Coveny J, Handsley E, Carter P. Marketing foods to children through product packaging : prolific, unhealthy and misleading. Public Health Nutrition 2012; 15(9):1763-70. https://doi.org/10.1017/S13689800120012 31 PMid: 22608304

17. Garcia AI, Morillo-Sanntander G, Parret A, Mutoro AN. Confused health and Nutritional claims in food marketing to children could adversely affect food choice and increase risk of obesity. Archives of Disease in Childhood 2019; 104(6):541-6.

https://doi.org/10.1136/archdischild-2018315870

PMid: 30530844

18. Department of Health. Nutrient profiling technical Guidance. United kingdom : 2011

19. WHO. Protecting children from the harmful effects of food and drink marketing. Available from: http://www.who.int/features/2014/ukfood-drink-marketing/en/ 
20. Lavirisa Z, Pravst I. Marketing of foods to children through food packaging is almost exclusively linked to unhealthy foods. Nutrients 2019; 11(5):1128.

https://doi.org/10.3390/nu11051128

PMid: 31117202 PMCid: PMC6566923

21. WHO. Vienna Declaration on nutrition and non-communicable diseases in the context of health. 2020. Available from: http://www.euro.who.int/_data/assets/pdf file
22. Labonte ME, Poon T, Gladanac B, Ahmed M, Franco-Arellana B, Rayner M. Nutrient profile models with applications in government led nutritional policies aimed at health promotion and noncommunicable disease prevention. A systematic review. Advances in Nutrition 2018; 9:741-88.

https://doi.org/10.1093/advances/nmy045 PMid: 30462178 PMCid: PMC6247226

23. WHO. Nutrient profile model for South East Asian region- 2017. ISBN 978-929022-544-7. 